\title{
The Effect of Microwave Radiation on the Growth of Staphylococcus Aureus
}

\author{
Kawthar Abduljabbar Boumarah ${ }^{1}$, Zahrah Ahmed Al Abdullah $^{2}$, Sara Sami Al Mubarak, \\ Sama Ahmed Alkhawaja ${ }^{4}$, Sayed Ibrahim Ali $^{5}$, Naglaa Ali Hassan Sidiq ${ }^{6}$ \\ ${ }^{1,2,3,4}$ Medical students at King Faisal University, College of Medicine, Saudi Arabia \\ ${ }^{5,6}$ King Faisal University, College of Medicine, Saudi Arabia
}

\begin{abstract}
The benefit and convenience of microwave ovens can't be denied. They produce obvious effects on the microbial growth. Sterilization and decontamination of food from microorganisms that cause food poisoning, such as staphylococcus aureus (S aureus) has very significant preventive and cost effective benefit. This study was performed to investigate the effect of microwave radiation (MR) on the growth of $S$ aureus. In order to observe the thermal effect of MR on the growth of these bacteria, $S$ aureus cultures were exposed to $\mathrm{MR}$ at $60 \mathrm{Hertz}(\mathrm{Hz})$, with different duration of time from 0 to 7 minutes (min). Compared to untreated control culture, cell viability was significantly reduced as the exposure time increased, with almost complete inactivation at 7 min. Data was analyzed by using SPSS version 19.0. Results concluded that there is a highly significant negative relationship between exposure time and quantity of bacteria. These findings suggest that MR could be an effective tool in inactivating different types of microorganisms.
\end{abstract}

Keywords: Microwave, Radiation, Staphylococcus Aureus

\section{Introduction}

Humans are exposed to many sources of radiation every day. The microwave radiation is one of the most important sources of radiation that encounter the human being every day. The microwave is non- ionizing electromagnetic waves with frequencies between 0.3 to 300 gigahertz $(\mathrm{GHz}){ }^{(1)}$

In recent years, the use of microwave has become common in the food industry for drying and thawing foods. ${ }^{(2-4)}$ Its advantage can be remarked as it only takes few minutes to heat food, which makes it a lot faster than the ordinary conventional oven. ${ }^{(5)}$ In particular, the microwave radiation has a great effect on microbial destruction in pasteurization of food. ${ }^{(3)}$

The microwave affects the growth of the microorganisms depending on the frequency of the radiation and the energy that is absorbed by the microorganisms. Therefore, when irradiating living organisms, microwaves produce two types of effect: thermal and non-thermal effect. Thermal effects are the consequences of absorption of microwave energy by cell molecules. It was suggested that killing of the microorganism is achieved by thermal effect of microwave exposure. ${ }^{(6-8)}$

One of the microorganisms that can cause food contamination is a type of bacteria called $\mathrm{S}$ aureus. ${ }^{(9)} \mathrm{S}$ aureus is one of the microorganisms that live on the body surface. It is catalase-positive, gram-positive cocci arranged in clusters. It can survive on dry surfaces for long period of time because of the thickened peptidoglycan layer and absence of outer membrane. ${ }^{(10)}$ Usually; it causes no illness in healthy people unless it is transmitted from contaminated food products, resulting in food poisoning. ${ }^{(11)}$

When S. aureus was exposed to microwave radiation of 2450 Megahertz (MHz), the viability of the bacteria decreased as exposure time increased. Complete inactivation of bacteria was reached after 110 seconds at a temperature of $61.4^{\circ} \mathrm{C}$. ${ }^{(12)} \mathrm{As}$ a result, it is clear that there is a significant relation between microwave radiation and the viability of $\mathrm{S}$. aureus, on the basis of duration of exposure.

Research on the effect of microwave on the growth of microbial cultures was published in biomedical journals indexed in Medline from 1966 to 2012. Microwaves produce obvious effects on the growth of microbial cultures, which vary from the killing of microorganisms to enhancement of their growth. ${ }^{(13)}$

The purpose of the present study is to detect the effect of the microwave radiation on $\mathrm{S}$. aureus bacteria at different durations of time in four cafeteria's microwaves at King Faisal University (KFU). That is, to see whether microwave radiation either kills or enhances the growth of S. aureus bacteria.

\section{Materials and methods}

An experimental study was conducted in four cafeteria's microwave and the lab microwave at KFU.

\subsection{Materials}

5 microwave ovens 60 hertz (Hz), 120 volt (V), swabs, blood agars (BA) homemade, mannitol salt agars (MSA) chapman agar, Scarlau 01-116-500, microscope slides, S. aureus sample; unknown patient sample and a $37 \mathrm{C}^{\circ}$ incubator.

\section{Experiment 1:}

At the beginning of a working day, four swabs were taken from each of four Microwave ovens in four different colleges, at different exposure times, making sixteen swabs. These swabs were taken from a predetermined location in the microwave plate at 0 seconds $(\mathrm{S}), 10 \mathrm{~s}, 50 \mathrm{~s}$ and $120 \mathrm{~s}$. The swabs were cultured in MSA and BA. Sixteen MSA plates 


\section{International Journal of Science and Research (IJSR) \\ ISSN (Online): 2319-7064 \\ Index Copernicus Value (2013): 6.14 | Impact Factor (2015): 6.391}

and eight BA ones were used and stored at $37 \mathrm{C}^{\circ}$. Results were opined after 24 hours.

\section{Microwave oven:}

Four Microwave ovens were used. They have a frequency of $60 \mathrm{~Hz}$ and $120 \mathrm{~V}$.

\section{Experiment 2:}

Towards end of the day, four swabs were taken from one microwave, cultured in MSA and BA and incubated at $37^{\circ} \mathrm{C}$. Procedure and setting were done exactly as the first experiment.

\section{In the laboratory}

\section{Experiment 3:}

A microwave oven with a rotating glass plate was used for microwave irradiation treatment. It has a frequency of $60 \mathrm{HZ}$ and $120 \mathrm{~V}$.

\section{Testing Laboratory S. aureus}

A loop of $\mathrm{S}$ aureus was diluted in $3 \mathrm{ml}$ of normal saline. One drop of the solution was added and spread onto each one of nine separate slides.

The slides were exposed to microwave radiation at different durations of time Table 1. Slide 1 was used as a control.

Table 1: $\mathrm{S}$ aureus inoculated-slides and the time of MR exposure

\begin{tabular}{|c|c|}
\hline Number of the Slide & MR Exposure Time $(\mathrm{min})$ \\
\hline 1 & $0 \mathrm{sec}$ \\
\hline 2 & $5 \mathrm{sec}$ \\
\hline 3 & $1 \mathrm{~min}$ \\
\hline 4 & $2 \mathrm{~min}$ \\
\hline 5 & $3 \mathrm{~min}$ \\
\hline 6 & $4 \mathrm{~min}$ \\
\hline 7 & $5 \mathrm{~min}$ \\
\hline 8 & $6 \mathrm{~min}$ \\
\hline 9 & $7 \mathrm{~min}$ \\
\hline
\end{tabular}

After exposure to MR for the specific time, a swab was taken from each slide and was cultured in BA. All samples were stored in $37 \mathrm{C}^{\circ}$ incubator for $24 \mathrm{~h}$.

\section{Results}

First and second experiments did not show significant growth of bacteria in BA and MSA cultures. Third experiment was done to confirm the effect of microwave radiation on $\mathrm{S}$ aureus bacteria, in the laboratory. The inactivation patterns of the microwave-radiated cells were investigated using cell suspensions of laboratory S. aureus samples.

There was significant reduction in bacterial culture after each exposure time Table 2. Figure 1, 2, 3, 4, 5. The longer the exposure time, the more the bacterial reduction. Almost complete bacterial inactivation was reached after 7 minutes of MR exposure. Figure 5.

Slides $3,4,5,6,7,8$ showed that increasing of the MR exposure time markedly reduce the viability of the bacteria Figure 2, 3, 4, 5.
Table 2: The time exposure and the estimated percentage of bacterial colonies. Value of test equal -0.997 . P-value $=$

\begin{tabular}{|c|c|c|}
\hline $\begin{array}{c}\text { Number of the } \\
\text { Slide }\end{array}$ & $\begin{array}{c}\text { MR Exposure Time } \\
\text { (min) }\end{array}$ & $\begin{array}{c}\text { Quantity of colonies } \\
\%\end{array}$ \\
\hline 1 & 0 & $100 \%$ \\
\hline 2 & 0.08 & $97 \%$ \\
\hline 3 & 1 & $80 \%$ \\
\hline 4 & 2 & $70 \%$ \\
\hline 5 & 3 & $55 \%$ \\
\hline 6 & 4 & $35 \%$ \\
\hline 7 & 5 & $27 \%$ \\
\hline 8 & 6 & $15 \%$ \\
\hline 9 & 7 & $0.01 \%$ \\
\hline
\end{tabular}

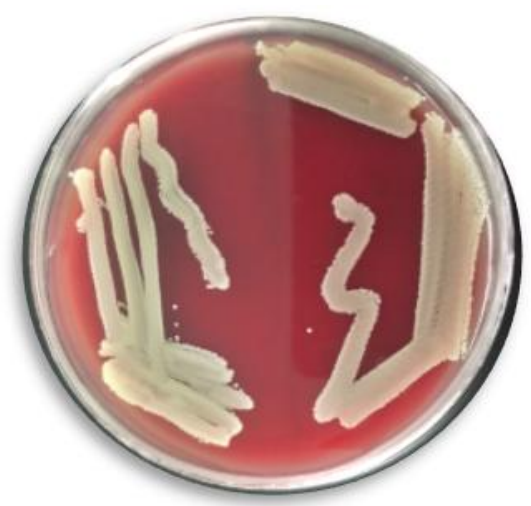

Figure 1: The growth of $S$ aureus in control group and 5S time exposure.

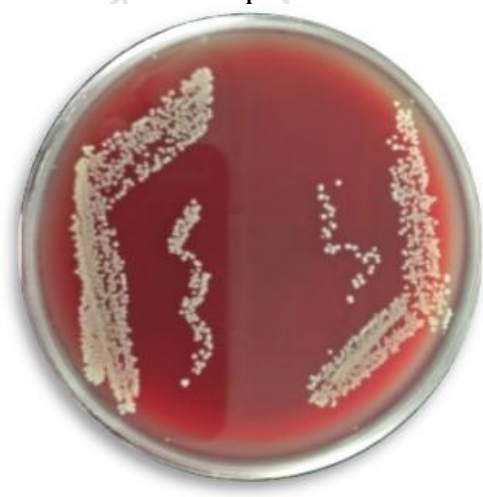

Figure 2: The effect of microwave radiation at $1 \mathrm{~min}$ and 2 min on growth of $\mathrm{S}$ aureus.

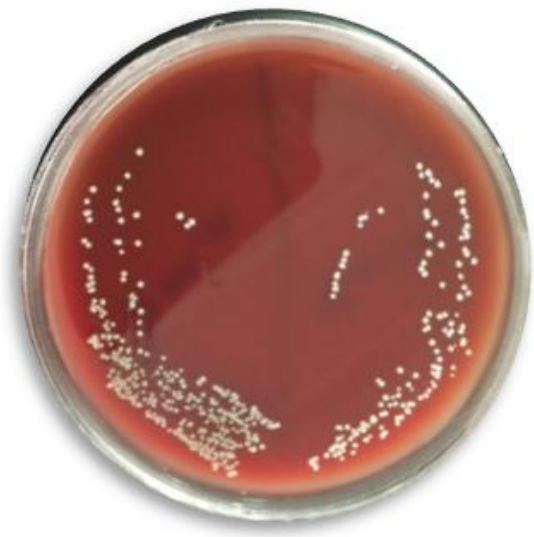

Figure 3: The effect of microwave radiation at $3 \mathrm{~min}$ and 4 min on the growth of $\mathrm{S}$ aureus 


\section{International Journal of Science and Research (IJSR) \\ ISSN (Online): 2319-7064}

Index Copernicus Value (2013): 6.14 $\mid$ Impact Factor (2015): 6.391

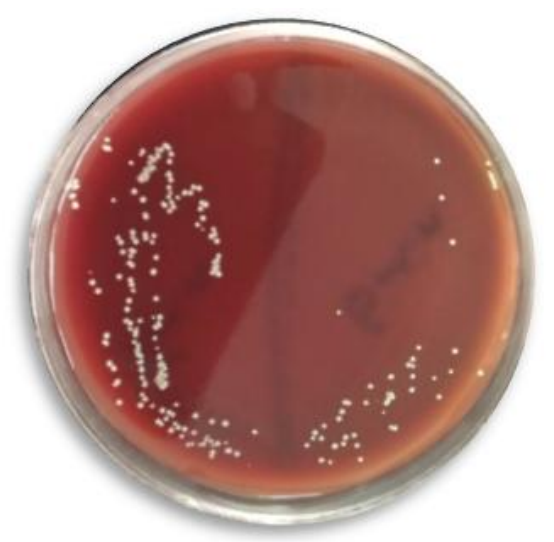

Figure 4: The effect of microwave radiation at 5 min and 6 min in the growth of $\mathrm{S}$ aureus

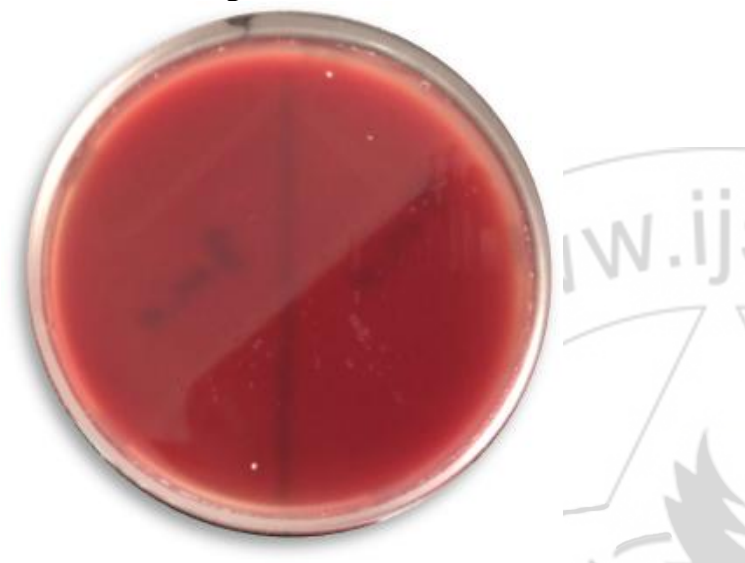

Figure 5: The effect of microwave radiation at $7 \mathrm{~min}$ on the growth of $\mathrm{S}$ aureus.

\section{Statistical Analysis}

The data was analyzed by SPSS version 19.0. A Pearson correlation test was used to determine the effect of microwave radiation on the growth of staphylococcus aureus. The value of the test was calculated as -0.997 , P-value equals 0.0001 . Therefore, it is safe to conclude that there is a highly significant negative relationship between time exposure and the quantity of S. aureus bacteria, see Figure 6.

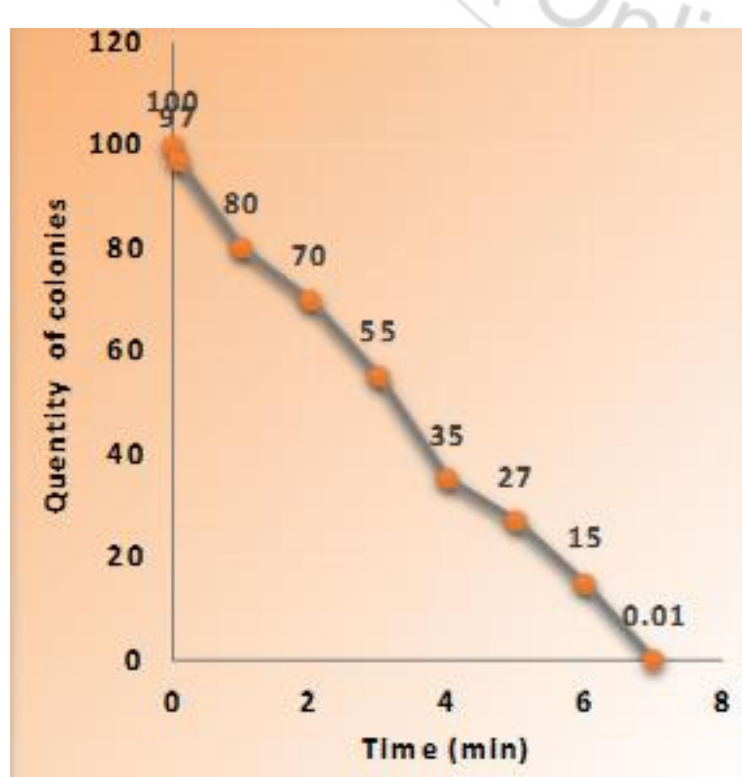

Figure 6: The relationship between MR exposure time and quantity of S. aureus

\section{Discussion and Conclusion}

Effect of MR on S. aureus bacteria varies from killing it to enhancing its growth. ${ }^{(13)}$ The different effects of MR appeared to depend upon the frequency and intensity of radiation. ${ }^{(14)}$

It has been determined that a significant decrease in S. aureus was observed as exposure time to MW radiation increased. The results demonstrate that the maximum destruction level occurred after 7-minute exposure time where almost all bacteria was killed.

Some researchers have suggested that high-frequency radiation kills the bacteria. ${ }^{(6-8,13)}$ As such, the expected outcome of these experiments was that MR contributed to the inactivation of bacteria. After conducting the experiments and analyzing results, it was clear that there was a close correlation between the results obtained from the experiments and the expected standard methods.

The results obtained from the first and second experiments showed no growth of bacteria on both BA and MSA, which can be explained as the constant use of MW oven by college students, has caused reduction of the microwave plate from bacterial contamination.

Third experiment showed that prolonged exposure to radiation is significantly related to the reduction of $\mathrm{S}$. aureus. Thus all conducted experiments were supportive of the original hypothesis. ${ }^{(6-8)}(12,13)$

Based on the results obtained, it is safe to conclude that microwave oven is an effective tool to use for heating and cooking food, as it causes killing of S. aureus bacteria, and thus, prevents $\mathrm{S}$. aureus food poisoning.

Research on MR effect on bacterial growth could be applied in many aspects. First, the effect of MR can be studied on other types of microorganisms, such as E. coli and viruses, which may contaminate food and cause illnesses as well. Furthermore, research can be conducted to determine whether bacteria is able to develop tolerance against high frequency radiation. Moreover, more experiments could be applied to see whether exposure to radiation is an effective method for sterilizing different equipment and tools in laboratories.

\section{References}

[1] Balbani A, Montovani J. Mobile phones: influence on auditory and vestibular Systems. Braz J Otorhinolaryngol. 2008;74:125-31.

[2] Kakita Y, Kashige N, Murata K, Kuroiwa A, Funastu M, and watanabe $\mathrm{K}$. Inactivation of Lactobacillus bacteriophage PL-1 by microwave irradiation. Microbiol. Immunol. 1995; 39:571-576.

[3] Rosenberg U, and Bogl W. Microwave thawing, drying, and baking in the food industry. Food Technol.1987;41:85-91. 
[4] Rosenberg U, and Bogl W. Microwave pasteurization, sterilization, blanching, and pest control in the food industry. Food Technol.1987; 41:92-99.

[5] Cross G, Fung D. The effect of microwaves on nutrient value of foods. Crit Rev Food Sci Nutr [Internet]. 1982 [cited 2016 Mar 27]; 16(4):355-81.

[6] Fung D, Cunningham F. Effect of microwaves on microorganisms in foods. J Food Prot.1980;43:641-650.

[7] Stiles M. Thermal inactivation and injury of Staphylococcus aureus. Ph.D. thesis. University of Illinois, Urbana; 1963.

[8] Vela G, Wu J. Mechanism of lethal action of 2,450-MHz radiation on microorganisms. Appl Environ Microbiol. 1979;37:550-553.

[9] Ananya M (MD). News medical [Internet]. [Place unknown]: Ananya M; [Date unknown] [updated 2012 Dec 9; cited 2016 Mar 27].

[10] Murray P, Rosenthal K, Pfaller M. Medical microbiology. $7^{\text {th }}$ Ed.Philadephia: Elsevier, 2013.p.174176.

[11]Centers for disease control and prevention. (Internet). (Place unknown) (Publisher unknown). (Date unknown). (Updated: December 21, 2015).Available at: http://www.cdc.gov/foodsafety/.

[12] Yeo CB, Watson IA, Stewart-Tull DE, Koh VH. Heat transfer analysis of staphylococcus aureus on stainless steel with microwave radiation. J Appl Microbiol [Internet]. 1999 Sep [cited 2016 Mar 27]; 87(3):396401.

[13] Slobodan M. Janković, Milorad Z. Milošev, Milan LJ. Novaković. The Effects of Microwave Radiation on Microbial Cultures. Hospital Pharmacology. 2014 may; 1(2):102-108.

[14] Webb SJ, Booth AD. Absorption of microwaves by microorganisms. Nature. 1969; 222:1199-1200 ne, Inc. 